\title{
Inclusão de alunos com deficiência em escolas do campo: desafios da docência em contextos multisseriados
}

\author{
Natalia Silveira Lima* \\ Daniela Regina Sposito Dias Oliva** \\ Claudete de Sousa Nogueira
}

\section{Resumo}

Os desafios de lidar com a diversidade na escola, em uma sociedade que valoriza padrões, que homogeneíza sujeitos, têm sido um dos principais temas levantados, tanto por parte de pesquisadores na área da educação como pelos segmentos que elaboram as políticas públicas em nosso país. As transformações docentes, em práticas contextualizadas às novas necessidades vigentes na era da pós-modernidade, ensejam melhorias no processo ensino-aprendizagem, bem como proporcionam condições de buscar a formação de profissionais conscientes e críticos no processo do ser social diante da diversidade. Com o intuito de aprofundar os estudos sobre essa temática, desenvolveu-se uma pesquisa que teve como objetivo investigar os desafios da prática docente no processo de inclusão de alunos com deficiência em escolas municipais do campo em Concórdia/ SC. Tais instituições apresentam, em suas estruturas e organizações, classes multisseriadas - unidocentes. A abordagem metodológica foi de natureza qualitativa, tendo como instrumentos de coleta de dados a entrevista semiestruturada e a observação não participante. Foram colaboradoras da pesquisa duas professoras de classes multisseriadas, identificadas como Açucena e Dália, as quais possuem a matrícula de alunos com deficiência e que compõem as Escolas do Campo de Concórdia. Como resultados, os temas principais emergidos nas entrevistas foram: 1) a valorização e o respeito às características e possibilidades de cada aluno; 2) concepção de sala de aula como espaço heterogêneo, rico em diversidades humanas; 3 ) o trabalho cooperativo como potencializador de ritmos e estilos de aprendizagens diferenciados; 4) formação continuada de professores: garantia de um "saber fazer". Espera-se que os resultados deste trabalho contribuam com a formação e atuação do educador no processo de inclusão de alunos com deficiência nos âmbitos escolares, em especial nas escolas de campo.

Palavras-chave: Diversidade. Educação do campo. Educação inclusiva. Formação de professores.

Recebido em 10 de novembro de 2012. Aprovado em 25 de fevereiro de 2013.

http://dx.doi.org/10.5335/rep.2013.3516

Especialista em Educação Inclusiva pela Faculdade de Tecnologia e Ciência de Salvador (FTC). Professora atuante na Secretaria Municipal de Educação de Concórdia e professora do Curso de Licenciatura em Educação Especial da Universidade do Contestado (UnC) - Campus Concórdia/SC, em convênio com o MEC/Capes. E-mail: natalia@concordia. sc.gov.br

** Mestra em Envelhecimento Humano pela Universidade de Passo Fundo (UPF). Docente e coordenadora do Curso de Licenciatura em Educação Especial na Universidade do Contestado (UnC) - Campus Concórdia/SC, em convênio com o MEC/Capes. E-mail: danielaoliva@unc.br

*** Pós-doutoranda em Educação pela Universidade Federal de São Carlos (UFSCar). É professora assistente doutora da Universidade Estadual Paulista Júlio de Mesquita Filho (Unesp) em Araraquara/SP. E-mail: amauri.claudete@ig.com.br 


\section{Introdução}

O tema diversidade é alvo de discussão tanto por parte de pesquisadores na área da educação como pelos segmentos que elaboram as políticas públicas em nosso país. Tal fato se deve, em parte, a esse momento de preparo para lidar com o diferente, o qual exige transformações das ações dos docentes, em práticas contextualizadas às novas necessidades, pois o processo ensino-aprendizagem necessita de profissionais conscientes e críticos no processo do ser social diante da diversidade.

Em acompanhamento e orientação de professores que atuam junto às crianças com deficiência em escolas municipais, foi possível identificar, em diferentes contextos, fatores que contribuem e que entravam os avanços para a construção de práticas inclusivas (VENDRAME, 2003). As escolas municipais do campo estão estruturadas e organizadas em sistemas multisseriados com um número de alunos que variam de oito a vinte, dependendo da comunidade onde a escola está inserida. Percebendo o contexto multisseriado como um espaço heterogêneo, rico em possibilidades e diversidades e oportuno para a prática pedagógica inclusiva é que surgiram a inquietação e o desejo de investigar o exercício pedagógico inclusivo em duas escolas do campo no município de Concórdia.

A educação do campo, nas últimas décadas, vem reivindicando, por meio de movimentos sociais e de discussões nacionais, uma educação específica para as comunidades e que, de acordo com o art. 28 da LDB 9394/96 (BRASIL, 2001a), promova as adaptações necessárias às peculiaridades da vida rural, de forma que os conteúdos curriculares e as metodologias atendam às reais necessidades e aos interesses dos alunos da zona rural (CALDART, 2003).

$\mathrm{O}$ acesso de alunos com deficiência em escolas regulares já é uma realidade em nosso país, e a sua participação e aprendizagem colidem com as formas tradicionais de organização das instituições, bem como com as práticas pedagógicas homogeneizadoras que igualam sujeitos. Por isso, a educação especial e a educação do campo vêm, ao longo das duas últimas décadas, reivindicando uma educação específica e identitária que considere em sua totalidade os modos de organização, cultura e valores das comunidades do campo (BRASIL, 2001b; CALDART, 2003).

A aprovação das Diretrizes Nacionais para a Educação do Campo, em 04/12/2001, proporcionou maiores discussões, fortalecendo os movimentos. Com efeito, esse fato legitimou as proposições da I Conferência Nacional da Educação do Campo (1998), com a proposta de construção de uma Política Pública de Educação Básica do Campo.

A necessidade de uma ressignificação sistêmica, conceitual e atitudinal também esteve presente nos diferentes contextos educacionais das pessoas com defi- 
ciência. Afinal, muitos dos conceitos e formas de atendimento a essas pessoas estiveram, historicamente, associados às expectativas sociais e aos modelos de homem e de normalidade constituídos em determinadas épocas da humanidade. Nesse sentido, cabe destacar que, assim como o conceito de deficiência está relacionado aos diferentes modelos e concepções de determinadas épocas históricas, o mesmo pode ser percebido com relação ao conceito e à prática da educação especial, na sua trajetória histórica.

Hoje, novas concepções acerca da pessoa com deficiência são formuladas. Com base em princípios inclusivos, acredita-se que todos somos diferentes, que cada sujeito é único e que a diversidade humana é um direito, e não uma condição. A abordagem inclusiva, segundo Sassaki (1997), está fundamentada no modelo social da deficiência e caracteriza-se como um processo ao qual a sociedade se adapta para poder incluir as pessoas com deficiências em seus setores, e estas, consequentemente, se preparam para assumir seus papéis sociais.

Por isso, é compreensível que, na prática, os processos de integração e inclusão coexistam por algum tempo, até que a integração seja totalmente substituída pela inclusão, o que passa a ser entendido como um grande desafio. Diante desse contexto, pontua-se como um dos desafios da educação inclusiva a superação de práticas tradicionais, removendo as barreiras nos processos de aprendizagem e valorizando a diversidade no contexto pedagógico. Sendo o aluno o centro do processo pedagógico, quanto mais diversas forem suas características e manifestações, maiores serão as possibilidades de estilos e ritmos de aprendizagens, motivações e interesses.

Durante muito tempo, a escola foi marcada por uma organização uniforme com critérios seletivos, quando o conteúdo curricular era o foco do processo de ensino-aprendizagem.

Segundo Mantoan,

[...] por esses e outros sérios entraves é que, à custa de muito esforço e perseverança, estamos vencendo as resistências de muitos para flexibilizar a organização escolar, já que sem a flexibilização as mudanças continuarão sendo unicamente de fachadas. A prática pedagógica baseada em princípios inclusivos deve atender a diversidade humana, utilizando-se de projetos pedagógicos amplos e diversificados e que se adaptem às distintas necessidades de todos os alunos. Isto implica uma maior flexibilidade nas situações de aprendizagens, ritmos, materiais e estratégias de ensino (2009, p. 17).

Conforme Duk (2005), fazer uso de estratégias diversificadas, dinâmicas de aprendizagem cooperativa, oportunizar momentos em que os alunos pratiquem e apliquem com autonomia o que foi aprendido, considerar a interdisciplinaridade são algumas dentre as várias estratégias de resposta à diversidade. 
Diante desse contexto, este trabalho teve como principal objetivo investigar os desafios da prática docente no processo de inclusão de alunos com deficiência em escolas municipais do campo de Concórdia/SC. Trata-se de uma pesquisa qualitativa, tendo como procedimentos para a coleta de dados, a entrevista semiestruturada e a observação não participante. A utilização da técnica de entrevista com os professores pode oferecer "informações que se referem diretamente ao indivíduo entrevistado, suas atividades, valores, opiniões, que só podem ser conseguidas com a contribuição dos atores envolvidos" (MINAYO, 2000, p. 108). Para o desenvolvimento da pesquisa foram percorridos os seguintes caminhos:

1 levantamento bibliográfico sobre o assunto;

2 contato com a secretaria de educação municipal, solicitando a autorização para a realização da pesquisa, a qual foi concedida;

3 contato com as professoras das escolas a fim de informar-lhes a respeito da pesquisa e solicitar a sua participação, mediante assinatura do termo de consentimento livre e esclarecido, obedecidas as normas da Resolução 196/96;

4 organização e realização das entrevistas não estruturadas com as professoras das escolas do campo, seguindo os preceitos éticos da pesquisa com seres humanos;

5 análise temática dos dados coletados, de acordo com Minayo (2000).

A entrevista envolveu questões referentes à escola, à formação, ao tempo de atuação das professoras em contextos multisseriados, às mudanças e permanências na prática pedagógica junto aos alunos com necessidades especiais, à concepção pedagógica que embasa o processo educativo inclusivo e aos desafios da docência frente à inclusão em escolas multisseriadas. Além da aplicação desse instrumento, foi realizada a observação não participante no contexto das salas de aula de ambas as escolas, por meio da qual se pôde captar vivências, acontecimentos e interações relevantes do cotidiano da prática educativa.

Após a coleta de dados, transcrição das entrevistas e análise temática, emergiram as seguintes categorias: 1) valorização e o respeito às características e possibilidades de cada aluno; 2) concepção de sala de aula como espaço heterogêneo, rico em diversidades humanas; 3 ) o trabalho cooperativo como potencializador de ritmos e estilos de aprendizagens diferenciados; 4) formação continuada de professores: garantia de um "saber fazer".

Conhecer o aluno, investigar suas habilidades e potencialidades, conhecer o repertório de informações já adquiridos são tarefas essenciais para que o professor possa planejar estratégias de ensino-aprendizagem que atendam a todos os alunos.

Quando questionada acerca de como ocorreu o processo de inclusão nas etapas iniciais de escolarização da aluna com deficiência, a professora Açucena assim falou sobre sua vivência prática: 
O conhecimento da realidade da criança foi um dos pontos primordiais para iniciar o trabalho e, principalmente, valorizar suas potencialidades construídas até então. O processo ocorre com normalidade e respeito ao seu desenvolvimento. É observado as potencialidades que a mesma possui e explorado com atividades e aberturas estratégicas para ampliar os conhecimentos contando com os demais colegas e as informações que os mesmos possuem, para valorizar as conquistas que todos juntos ampliam, sem diferenciar ou valorizar a promoção de um ou de outro, mas desafiar cada um dentro de suas potencialidades individuais, dando assim o real significado do aprendizado coletivo.

No relato de Açucena, é possível perceber sua preocupação em respeitar e valorizar cada aluno com suas potencialidades e vivências já construídas, o que remete a um dos principais desafios da educação inclusiva, que é considerar a diversidade como uma oportunidade para enriquecer os processos de aprendizagem.

Diante desse desafio, o processo inclusivo exige uma nova visão com relação à educação comum, baseada na heterogeneidade, considerando que cada aluno tem uma capacidade, um interesse, uma experiência pessoal; ou seja, a diversidade humana e sociocultural é considerada uma característica normal no contexto escolar. Dada essa concepção, Guijarro afirma que "a ênfase está em desenvolver uma educação que valorize e respeite as diferenças, vendo-as como uma oportunidade para otimizar o desenvolvimento pessoal e social e para enriquecer os processos de aprendizagem" (2005, p. 10).

Tal diversidade somente será entendida como um fator enriquecedor no processo de ensino-aprendizagem, se o professor valorizá-la como tal. Afinal, sendo o aluno um dos principais atores do processo educativo, quanto mais diversas forem suas características e manifestações, tanto mais os processos educativos serão aprimorados como consequência dessa diversidade de capacidades, interesses, ritmos que cada um manifesta.

No curso da narrativa, o desvelamento dos desafios da prática pedagógica diante do processo de inclusão emergiu da fala de Dália. Ela relata que emprega o planejamento diário como uma ferramenta útil nesse processo em sua prática cotidiana:

Percebi que ao desenvolver as atividades em grupo o crescimento era significativo, e isso colabora com as práticas realizadas nas diferentes áreas do conhecimento. O planejamento diário é um fator que vem mostrar as possibilidades diárias de observação e conhecimento que tanto a aluna com necessidades especiais, como os demais desenvolvem, pois ao propor as atividades o desafio é estar ampliando suas potencialidades e não trabalhar acerca das dificuldades. Eu ofereço várias formas de explorar o conhecimento e cada aluno vai perceber de acordo com suas referências e vivências a que melhor se destaca. São pequenas particularidades, mas que fazem a diferença de cada sujeito. Eu posso trabalhar o mesmo conhecimento com todos. A diferença vai estar no que eu quero como meta e objetivo com cada um. 
Essa questão remete à análise de um desafio de grande relevância para a prática pedagógica inclusiva, que é o de flexibilizar e diversificar o trabalho pedagógico em grupos assumidamente heterogêneos. Rodrigues refere que a dimensão das competências se relaciona com o "saber fazer, isto é, o conhecimento que o professor deve ter para conduzir, com sucesso, processos de intervenção em contextos assumidamente diversos [...] podemos dizer 'assumidamente' porque todos os grupos são heterogêneos em termos de aprendizagem; a questão é se nós os tratamos como tal [...]" (RODRIGUES, 2008, p. 13).

Em um dos momentos de observação em contexto escolar, foi possível acompanhar a realização de uma atividade de sistematização dos aspectos mais importantes percebidos pelos alunos a respeito de um conteúdo trabalhado pela professora Açucena, o qual tinha como enfoque a "Reciclagem". Antes de iniciarem as atividades, a professora fez uma retrospectiva desse conteúdo, por meio de questionamentos e problematizações.

A proposta consistiu na escuta aos alunos, relatando sobre os meios pelos quais eles obtiveram mais claramente o aprendizado acerca do tema trabalhado. Aqueles que escolhessem as mesmas estratégias poderiam realizá-las em grupo, ou, se preferissem, individualmente. E assim se procedeu, dando vez às explanações, um a um.

Questionada sobre os desafios da prática pedagógica no processo de inclusão em contexto multisseriado, a professora Açucena assim responde:

Assumir o papel professor, diretor, cozinheiro, zelador entre outros que temos nas escolas do centro da cidade está no diferencial do professor de escolas multisseriadas. Pois exercer todas estas funções leva a que se desenvolva algo muito especial em cada escola, que é a colaboração e o trabalho coletivo, sendo que uma família fica responsável pelo pão que é servido no lanche; a cada quinze dias duas mães organizam a limpeza geral da escola, todos os dias os ajudantes organizam a sala [...] e assim ocorre a inclusão social, tendo o trabalho como fonte de respeito e solidariedade coletiva.

Além da possibilidade de oportunizar situações pedagógicas que proporcionam o trabalho colaborativo entre os alunos, Açucena refere outros ganhos: "Percebi que ao desenvolver as atividades em grupo o crescimento era significativo e isso colabora com as práticas realizadas nas diferentes áreas do conhecimento". O mesmo acontece nas questões relacionadas com as atividades administrativas da escola, pois, em conjunto, os pais e a comunidade dão apoio para o seu desenvolvimento, o que, sem dúvida, enriquece o contexto escolar e possibilita a articulação da escola com o seu entorno.

Verifica-se, assim, que a aprendizagem baseada na cooperação possibilita maior otimização do tempo e do espaço escolar, pois favorece maior autonomia entre os alunos, disponibiliza mais atenção por parte do professor para as situações 
especiais, bem como para as dificuldades que emergem no processo de aprendizagem. No entanto, é importante ressaltar que as estratégias de ensino cooperativo somente se tornarão eficazes se forem planejadas e avaliadas constantemente, com o propósito de averiguação de sua funcionalidade, na medida em que contribuem para o desenvolvimento do aluno. Para tanto, porém, essas estratégias precisam fazer parte de um processo sistematizado e bem coordenado.

Diante de tais desafios, é possível destacar que os participantes reportam a necessidade de uma nova prática educativa que ensine e eduque todos os alunos, reconhecendo as experiências e diferenças individuais, o trabalho cooperativo e a flexibilização curricular, como valores a serem considerados no desenvolvimento e na materialização dos processos de ensino-aprendizagem inclusivos.

Conceber a educação inclusiva como novo paradigma educacional que reconhece o direito de todas as crianças e jovens de compartilharem o mesmo ambiente educativo, em que todos são valorizados, independentemente de suas condições físicas, cognitivas, sociais, raciais, entre outras, exige uma reformulação na organização dos sistemas educacionais, nas suas práticas e, principalmente, nas concepções que alicerçam esse novo pensar. Os princípios que norteiam a educação inclusiva reconhecem essa necessidade da reconstrução da escola e de suas práticas. Dália, ao ser questionada sobre a concepção pedagógica que embasa sua atuação docente, relata:

Percebe-se que, para ser um professor inclusivo, deve-se ter claros alguns fatores e acreditar nas possibilidades e potencialidades dos alunos com necessidades educacionais especiais, sem excluí-los das ações básicas sociais. A aprendizagem sequencializada, baseada em avaliações específicas, individuais e em planejamentos significativos, com princípios científicos de desenvolvimento, tendo assim provavelmente resultados positivos, pois está-se [sic] respeitando o tempo e as fases que cada indivíduo possui. [...]. O professor deve conhecer as sequências de desenvolvimento nas diferentes áreas, pois o currículo não pode ser um livro de receitas; deve, sim, conter as bases científicas do desenvolvimento, valorizando os períodos de cada indivíduo.

Encontram-se diluídos, nos apontamentos de Dália, vários elementos que denotam sua concepção quanto ao processo educativo-inclusivo. Quando essa descreve sobre a clareza dos fatores, possibilidades e potencialidades dos alunos e ressalta a importância da não-exclusão, denota-se a valorização do desenvolvimento de potencialidades que os alunos apresentam, ao invés de focalizar seus limites e dificuldades.

A respeito desse tema, Duk destaca que, "em uma escola inclusiva, a situação de desvantagem ou deficiência do educando não deve ser enfatizada" (2005, p. 60), mas sim centrar em apoio às qualidades e às necessidades de cada um e de todos os alunos da escola (DUK, 2005; BEYER, 2005). 
Outra concepção presente na resposta da professora refere-se ao conceito de aluno, quando referencia "o tempo e as fases que cada indivíduo possui". Segundo os princípios inclusivos proclamados pela Declaração de Salamanca (UNESCO, 1994; CORDE, 1994), cada criança tem características, interesses, capacidades e necessidades de aprendizagem que lhe são próprias, ou seja, cada sujeito é único, e é essa diversidade humana que enriquece o processo educativo.

Observando a prática pedagógica da professora em contexto escolar, foi possível identificar, em seu planejamento, uma motivação para a realização da aprendizagem cooperativa (apoio aluno-aluno, aluno-professor), a qual pressupõe a valorização atribuída pelo docente à contribuição do saber de cada aluno no processo de aprendizagem, e não somente ao saber que ele próprio transmite.

Segundo Duk:

As estratégias de aprendizagem cooperativa têm efeitos positivos no rendimento escolar, na autoestima, nas relações sociais e no desenvolvimento pessoal. A utilização desse tipo de técnica pressupõe uma grande ajuda para o professor, por facilitar o trabalho autônomo dos alunos, permitindo-lhe dedicar mais atenção àqueles que dela mais necessitam $(2005$, p. 176).

Tais colocações reportam à análise da caracterização das turmas na perspectiva de educação inclusiva, assumindo estas uma nova concepção, a de turmas heterogêneas. E é nessas turmas que o trabalho cooperativo terá resultados significativos, ou seja, na presença de diferentes experiências, culturas e conhecimentos por parte de alunos e professor. De acordo com Mantoan, "trocas, contudo, implicam em desenvolvimento quando envolvem diferenças. De fato, trocas entre iguais não causam desequilíbrios e, portanto, não provocam avanços" $(2004$, p. 67).

Essas concepções somente terão seu verdadeiro sentido se forem somadas a uma postura crítico-reflexiva por parte do professor. Quando menciona, na última questão apresentada, que "o currículo não pode ser um livro de receitas", a professora Dália sugere ter a compreensão de que o professor é um (re) construtor e mediador de estratégias, as quais serão significativas se corresponderem às reais necessidades e aos interesses de cada aluno, portanto, o que pode ser significativo para um pode não ser para outro.

A nova perspectiva da educação inclusiva implica mudanças substanciais na formação do professor e na prática pedagógica, porque reconhece a necessidade de reconstrução do pensar do professor, levando-o a estabelecer como fundamental a resolução de problemas em grupo. Ainda, visa à colaboração, elimina crenças e conceitos com relação às dificuldades e à busca de novas alternativas que permitam aos alunos alcançar o sucesso.

Observar a prática pedagógica do professor no contexto pedagógico multisseriado possibilitou a sistematização e análise de diversos desafios frente ao processo 
educativo-inclusivo, os quais remetem para a necessidade de superação de práticas tradicionais que supervalorizam a competitividade em detrimento da colaboração; a homogeneidade no lugar da valorização das diferenças e, principalmente, de uma ressignificação das concepções acerca dos principais elementos constitutivos do processo educativo, ou seja, o sujeito (aluno), o pensar e o fazer do professor, a flexibilização curricular e o contexto educativo.

\section{Conclusões}

O objetivo de realizar essa investigação foi alcançado. Percebendo o contexto multisseriado das escolas do campo no município de Concórdia como espaço heterogêneo e diversificado - portanto, bastante oportuno para a realização de práticas pedagógicas inclusivas -, procurou-se, mediante a realização de uma pesquisa qualitativa, elencar elementos que pudessem apontar desafios a serem enfrentados pelas professoras no processo de inclusão de alunos com deficiência em tal meio.

A observação da prática pedagógica no contexto multisseriado, bem como a realização de uma entrevista não estruturada oportunizaram o levantamento de dados que, posteriormente, foram analisados e teoricamente fundamentados. Diante do desafio de conceber a educação comum como um espaço de heterogeneidade e diversidade, que respeita e valoriza cada aluno com suas potencialidades e vivências, pode-se destacar que a ênfase dessa educação está em ampliar tais características, otimizando o desenvolvimento pessoal e social e, principalmente, enriquecendo os processos de ensino e aprendizagem.

Os resultados obtidos pela análise dos dados comprovam que a prática pedagógica e a concepção acerca do processo educativo-inclusivo, apresentadas pelas professoras, oportunizam situações inclusivas no contexto multisseriado, possibilidades que beneficiam não somente os alunos com deficiência, mas também todos os alunos ali inseridos.

A flexibilização de estratégias, de mediações necessárias a uma prática inclusiva passa a ser explorada e concretizada, favorecendo a aprendizagem de um maior número de alunos. Foi possível perceber, nos momentos de observação, oportunidades em que as crianças eram estimuladas a desenvolver suas potencialidades, diversificando atividades em que as diferentes aptidões eram valorizadas, na medida em que uma sabia escrever bem, outra sabia desenhar, outra tinha muitas ideias. Nesse ambiente, a criança sentia-se estimulada a aprender algo que até então era difícil ou desconhecido.

Para as professoras que vivenciam o processo de inclusão, tal contexto é entendido como propício à prática inclusiva, além de ser desafiador, pois requer uma 
nova postura frente à realização de práticas pedagógicas tradicionais, uma postura que valoriza padrões e ritmos de aprendizagens. Nesse sentido, concorda-se com Mantoan, quando defende a tese de que a diversificação de atividades é o que faz a diferença em um ensino escolar que reconhece e valoriza os conhecimentos que o aluno é capaz de produzir, segundo suas potencialidades.

Os resultados mostram, ainda, que a prática do trabalho cooperativo oportuniza maior autonomia para o aluno, pois permite que os alunos trabalhem juntos para cumprir objetivos e tarefas compartilhados. Tal estratégia favorece, igualmente, a possibilidade de mediação mais direta para os alunos que dela necessitam.

Concluindo, registra-se o que está evidente, o que se conseguiu esclarecer, ou seja, que a educação inclusiva se coloca como um novo princípio educacional, cujo conceito fundamental defende a heterogeneidade como situação provocadora de interações entre os alunos que possuem características pessoais, sociais, culturais das mais diversas. Enfatiza-se, ainda, que esse princípio propõe que a prática pedagógica se amplie e enriqueça frente às diferenças do alunado.

Em contrapartida, deixa-se registrado, também, o que não se conseguiu desvendar, isto é, as mudanças não captadas, o que ainda permanece, ou seja, o processo de exclusão educacional que no passado envolveu grande número de pessoas, entre elas, as com deficiência, que ainda hoje vivenciam essa situação, juntamente com as camadas menos favorecidas da sociedade.

Não se trata, contudo, da ausência de direitos; pelo contrário, a legislação, anteriormente teorizada, considera todas as crianças sujeitos de direito e provê a obrigatoriedade de sua educação. Assim, repensando as desigualdades sociais estabelecidas pela estruturação de classes, a educação inclusiva tem como propósito deixar de ser tratada como algo à parte, para ser entendida como uma realidade a se superar enquanto cultura excludente, a fim de se ver, finalmente, substituída pelo direito de oportunidade e valorização em um espaço onde a diversidade é vista como matéria-prima para a aprendizagem.

Acredita-se que o trabalho aqui sistematizado, de alguma forma, contribuirá para o processo de formação de profissionais da educação que têm como propósito aprofundar o conhecimento na área da inclusão, por ser constituir uma experiência vivida de prática inclusiva.

O trabalho diário das professoras, bem como sua disponibilidade para atenderem aos questionamentos da entrevista, foi imprescindível para o desenvolvimento desta pesquisa. Sem dúvidas, a prática no dia a dia de uma escola multisseriada é muito mais complexa do que o recorte que se realizou num determinado momento de sua história como educadoras. Contudo, não deixou de adquirir importância, pois apresenta, em seu corpo, conhecimentos historicamente acumulados que enriqueceram a sua análise. 


\section{Inclusion of students with disabilities in the field school: challenges of teaching in multiseriates contexts}

\section{Abstract}

The challenges of dealing with diversity in the school, in a society that values standards, which homogenizes subjects, have been one of the main issues raised, both by researchers in the field of education as the segments that produce the policies in our country. The teatchers transformations, in the new needs prevailing in the era of postmodernity have inspired improvements in the teaching-learning process and provide conditions to seek training professionals aware and critical in the process of being on social diversity. The present study aimed to investigate the challenges of teaching practice in the process of inclusion of students with disabilities in public schools in the Field of Concordia-SC. Such institutions have structures in their multigrade classes and organizations - with one teatcher for all. The methodological approach was qualitative in nature, with the instruments to collect data, semi-structured interviews and non-participant observation. We research subjects, two teachers of multigrade classes, Azucena and Dalia, which have enrollment of disabled students and the schools that comprise the Concordia Field. It was observed that as a result the main themes emerged from the interviews were: 1) Valuing and respecting the characteristics and capabilities of each student, 2) Design of classroom space as heterogeneous, rich in human diversity, 3) Cooperative work as a potentiator rhythms and different styles of learning, 4) continuing training of teachers: ensuring a "know-how". It is hoped that the results of this study contribute to the formation and performance of the teacher in the process of inclusion of students with disabilities in school areas, especially in schools field.

Keywords: Diversity. Field Education. Inclusive Education. Teacher training.

\section{Referências}

BEYER, H. O. Inclusão e avaliação na escola: de alunos com necessidades educacionais especiais. Porto Alegre: Mediação, 2005.

BRASIL. Lei no 9394 / 96 - Lei de Diretrizes e Bases da Educação Nacional (LDB). Brasília: Câmara dos Deputados, Coordenação de Publicações, 2001.

. Diretrizes operacionais para a educação básica nas escolas do campo: educação do campo. Brasília, 2001.

CALDART, R. S. A escola do campo em movimento. Currículo sem Fronteiras, v. 3, n. 1, jan./jun. 2003.

CONFERÊNCIA NACIONAL DA EDUCAÇÃO DO CAMPO: por uma educação básica do campo, 1, 1998, Luziânia, GO. Anais... Luziânia, GO: UnB, 1998.

COORDENADORIA NACIONAL PARA INTEGRAÇÃO DA PESSOA PORTADORA DE DEFICIÊNCIA (Corde). Declaração de Salamanca e linhas de ação. Brasília: Independência, 1994. 
DUK, C. Educar na diversidade: material de formação docente. Brasília: Ministério da Educação, Secretaria de Educação Especial, 2005.

GUIJARRO, M. R. B. Inclusão: desafios para os sistemas educacionais. Brasília: MEC/SEESP, 2005. (Ensaios Pedagógicos - Construindo Escolas Inclusivas).

MANTOAN, M. T. E. Ser ou estar, eis a questão: explicando o déficit intelectual. Rio de Janeiro: WVA, 2004. 2009. . A escola flexível e a pedagogia das diferenças. Revista Pátio, ano XII, jan.

MINAYO, M. C. de S. Pesquisa social: teoria, método e criatividade. 17. ed. Petrópolis, RJ: Vozes, 2000.

RODRIGUES, D. Desenvolver a educação inclusiva: dimensões do desenvolvimento profissional. Revista Inclusão, v. 4, n. 2, jul./out. 2008.

SASSAKI, R. K. Inclusão: construindo uma sociedade para todos. Rio de Janeiro: WVA, 1997.

UNESCO. Declaração de Salamanca. Genebra: UNESCO, 1994.

VENDRAME, L. Ensino fundamental I: escolas isoladas municipais - pensando a educação democrática. Caderno Pedagógico 1, Semed, Concórdia, 2003.

. Educação do campo: limites e possibilidades da proposta de Concórdia (SC) a partir da concepção de escola unitária de Gramsci. Curitiba, 2007. Disponível em: <http://www.acervo.epsjv.fiocruz.br/beb/textocompleto/mfn12097>. Acesso em: 11 nov. 2011. 